\title{
ENSAYO
}

\section{CÓDIGOS INTERVINIETES EN EL DISCURSO DOCENTE QUE FACILITAN EL APRENDIZAJE DEL ADULTO APRENDIZ}

\section{CÓDIGOS INTERVINIETES EN EL DISCURSO DOCENTE QUE FACILITAN EL APRENDIZAJE DEL ADULTO APRENDIZ}

PAUlina MORAles H. ${ }^{1}$, JOSÉ ÁNGEL BERMÚDEZ G. ${ }^{2}$, JEAN CARLOS GARCÍA Z. ${ }^{3}$

Recibido: 15 de junio de 2018 Aceptado: 22 de octubre de 2018

\footnotetext{
${ }_{1}^{1}$ Pontificia Universidad Católica del Ecuador, Facultad de Ciencias de la Educación, Quito, Ecuador (pmorales048@puce.edu.ec)

2 Pontificia Universidad Católica del Ecuador, Facultad de Ciencias de la Educación, Quito, Ecuador, (jbermudez647@puce.edu.ec)

${ }_{3}^{3}$ Pontificia Universidad Católica del Ecuador, Facultad de Ciencias de la Educación. Quito, Ecuador, (jgarcia493@puce.edu.ec)
} 
네lㅔ 260 


\section{ENSAYO}

\section{CÓDIGOS INTERVINIETES EN EL DISCURSO DOCENTE QUE FACILITAN EL APRENDIZAJE DEL ADULTO APRENDIZ}

\section{CÓDIGOS INTERVINIETES EN EL DISCURSO DOCENTE QUE FACILITAN EL APRENDIZAJE DEL ADULTO APRENDIZ}

Paulina Morales H., José Ángel Bermúdez G., Jean Carlos García Z.

Palabras clave: discurso, docente, códigos, aprendizaje, adulto aprendiz, semiosis.

Keywords: discourse, teacher, codes, learning, adult learner, semiosis. adulto aprendiz, semiosis.

\section{RESUMEN}

En las aulas universitarias se dan procesos de comunicación de vital importancia: el discurso del profesor, el significado de las palabras y los distintos códigos sociolingüísticos que son interpretados por los alumnos. Puede que estos no sean comprendidos y generen signos más o menos coherentes con el objeto de estudio o el referente que el docente está dando a conocer, por lo que el proceso comunicativo puede causar falta de comprensión de los distintos 
saberes. El presente estudio se origina gracias al objetivo de describir los diferentes códigos que intervienen en el discurso del profesor que favorecen o que no permiten el aprendizaje del adulto como aprendiz. El camino metodológico para alcanzar los propósitos de dichos estudios es la documental tipo ensayo. A lo largo de nuestro discurso develamos que ninguno de los constructos y elementos del discurso pedagógico están aislados, y que la descripción de los diferentes códigos se hace a través de un enfoque introspectivo vivencial, por lo que no es estático, ya que la realidad es ontológica y representa una realidad dinámica y cambiante. Cada código funciona asociado y relacionado con el otro y, así, sucesivamente, para lograr interpretar el proceso aprendizaje que, una vez comprendido, da inicio a mucho más en un proceso de semiosis cognitiva.

\section{SUMMARY}

Communication processes of vital importance occur in university classrooms, such as the professor's speech: the meaning of the words and the different sociolinguistic codes interpreted by the students may not be understood and may also generate signs that are consistent with the object of study or the reference being used by the professor. This communicative process may result in an inability to understand different types of knowledge; all of which leads to this study, whose objective is to describe the different codes that enter the instructor's discourse, and which do, or do not, favor the acquisition of knowledge by the adult learner. The methodological format for achieving the aims of these studies is the documentary-type essay. In the course of our analysis, we reveal that none of the constructs and elements of pedagogical discourse are isolated, and the description of the different codes is carried out through an experiential introspective approach. As such, it is not static, since reality is ontological and represents a dynamic and changing reality. Each code functions in association with and in relation to the other code, and so on successively, to achieve interpretation of the learning process that, once understood, starts another process, and another, in a process of cognitive semiosis. 


\section{INTRODUCCIÓN}

El funcionamiento de la sociedad es posible gracias a la comunicación, la cual consiste en el intercambio de mensajes entre los individuos, la transmisión de información y el entendimiento mediante el uso de signos comunes y convencionales que pueden ser lingüísticos o no. Los signos no lingüísticos como los gestos, los colores de la ropa y de los símbolos superpuestos, a veces, otorgan más información que las frases y las oraciones. Según Ribeiro (2000), "en realidad las palabras apenas representan el siete por ciento de la capacidad de influencia de las personas" (p. 59). Por lo tanto, en los procesos de comunicación los gestos son un factor determinante del mensaje.

Parecería que se da poca importancia a la lengua y a la conformación de los discursos, ya que en varios procesos comunicativos se usan muy pocas palabras para comunicarse. Según Grijelmo (2008), "el vocabulario de las personas se reduce paulatinamente lo que redunda en la disminución de las ideas" (p. 29) y no se toma en cuenta que los discursos son el contexto perfecto para definir y analizar a una comunidad que habla un mismo idioma. En ella se retrata a los políticos, deportistas, actores, vendedores, profesionales, estudiantes o profesores.

A pesar de que todos los procesos sociales se basan en la comunicación, probablemente el código lingüístico o el desarrollo del idioma no sea tan tomado en cuenta, tanto en su corrección como en su propiedad, lo que ocasiona problemas de comunicación, la falta de comprensión de los contextos de los actores en el proceso comunicativo y la decodificación de los signos utilizados. Los interlocutores del proceso deben usar los códigos comunes y convencionales de la comunicación, que no son solo lingüísticos.

Las palabras y los discursos de las personas los definen culturalmente $y$, con ellos, se puede determinar su formación y su procedencia. Todo el quehacer humano, en sus diferentes manifestaciones y contextos sociales, está mediado por el lenguaje y la realidad educativa no es una excepción. Los hábitos lingüísticos sociales se adquieren desde niños y se desarrollan en los hogares mediante la imitación de lo que se escucha en el entorno familiar o en los ámbitos educativos con los discursos del profesor. La manera de hablar de sus educadores es determinante para la comprensión del alumno. Vygotsky (1979) fundamenta, desde la psicología, el lugar que ocupa la mediación que provoca el lenguaje en el aprendizaje y muestra la necesidad que debe recorrer el alumno en lo que ya sabe y lo que puede llegar a aprender 
con la ayuda del otro.

Muchas veces el profesor de nivel universitario, considera de manera tácita cierto manejo de la lengua y signos lingüísticos convencionales por parte del alumno y elabora mensajes con palabras incomprensibles. Incluso, cuando usa inadecuadamente los actos de habla, lo que causa una predisposición negativa hacia la asignatura.

Este ensayo se enmarca en una concepción de la didáctica de las ciencias, dedicada al análisis e investigación de la multi-dimensionalidad de los procesos de enseñanza y aprendizaje. Su una finalidad su puramente instrumental, es decir, su didáctica, y la semiótica como disciplina que determina los contextos (situacional, lingüístico y mental), ponen en común o en signos convencionales el objeto del conocimiento, tanto para el profesor como para el alumno.

El alumno está inmerso en una sociedad que maneja cierto discurso y que, generalmente, el profesor desconoce porque se mueve en otro tipo de lenguaje. Así lo afirma también Carreter (s/f) (citado por Grijelmo 2008) "la muestra del retroceso es que multitud de chicos, incluso universitarios, no entienden el lenguaje del profesor. Son generaciones de jóvenes mudos, que emplean un lenguaje gestual, interjectivo y de empujón" (p. 125). Esto muestra que hay un divorcio entre el lenguaje del profesor y el del alumno, aun cuando el lenguaje y sus signos lingüísticos sean convencionales, porque no hay una conformidad de conocimientos y de entorno social.

Un informe oficial sobre la enseñanza secundaria en España lo corrobora (Arroyo, citado por Grijelmo, 2008). En el estudio, se evidencia que 5 de cada 100 estudiantes comprenden la lógica de los acentos, el 72\% se enreda con la $h$ y el $53 \%$ confunde la II con la $y$. En un dictado de 71 palabras los alumnos cometieron una media de cinco faltas con las tildes sobre un total de 20 posibles; únicamente el 18\% de alumnos es capaz de elaborar un relato bien desarrollado y, por último, solo uno de cada cuatro alumnos reconoce las ideas secundarias y los enunciados de sintaxis compleja. El modo particular y coloquial de hablar de los jóvenes, unido a frecuentes cambios de tema, marca diferencias con los discursos de los adultos y, más aún, con el de los profesores.

Según Grijelmo (2008), "los jóvenes exhiben un mayor empleo de muletillas y un estilo verbal menos cualitativo (menos adjetivos y más verbos) y, por lo tanto, más pobre en vocabulario" (p. 22). Las relaciones lingüísticas entre profesor y alumno conllevan una serie de negociaciones lingüísticas que permiten la circulación del conocimiento en el marco de contextos personales, institucionales y sociales que no son los mismos, lo que 
ocasiona una inadecuada interpretación de los códigos. Si bien se han realizado investigaciones sobre la incidencia del discurso del profesor en el alumno desde diferentes perspectivas como la pedagógica, psicológica o sociolingüística, se han propuesto análisis poco específicos respecto de lo que ocurre con la construcción del conocimiento científico por parte del alumno y las escasas teorizaciones sobre las situaciones particulares en que estos se generan. Por ello, es necesario conformar una explicación de tales hechos, es decir, del significado que el alumno aprehende como producto del proceso cognitivo al que se enfrenta en el aula.

Definir este proceso pedagógico como un ajuste de la semiosis cognitiva resulta necesario. Según Gardner (1987) hay que determinar críticamente la eficacia de los mensajes ya producidos y si entre determinados mensajes y sus correspondientes interpretaciones se da o no este acuerdo. De igual modo, es imprescindible constatar si determinada selección y contextualización de entidades (signos, producto, idea, comportamiento) generan en el intérprete (alumno) la misma significación que intentò atribuir su productor (profesor). Habría que añadir, además, una pregunta: ¿cómo funciona este proceso y qué elementos intervienen?

El profesor previamente ha he- cho una semiosis inferencial del objeto de estudio que va a ser transmitido hacia el estudiante. Este, a su vez, tendrá que hacer el mismo proceso para formarse un nuevo signo en su mente o interpretante.

Esta conceptualización, basada en la semiótica para explicar el proceso del aprendizaje, está acorde a la definición del signo como elemento tríadico (Peircesf. citado por Cobley y Jansz, 2000). Toma en cuenta la naturaleza del interpretante, que pueden o no coincidir con el signo del profesor y solo puede esperarse concretar este ajuste favoreciendo su evolución en el sentido deseado. Dicho de otra manera, se debe crear las condiciones, sea mediante un cambio de hábito o un hábito nuevo en su manera de percibir al conocimiento $u$ objeto presentado. Esto permite al estudiante la posibilidad de que este se forme su propio interpretante, entendiéndose "el interpretante como el nuevo signo en su mente, el nuevo concepto en su mente", (Peirce. s/f citado por Greimas, 1990, p. 43).

Mediante la institución de situaciones nuevas puede esperarse, sobre la base de los interpretantes adquiridos por los alumnos, ampliar y reforzar los hábitos existentes tanto como sea necesario. Esta actitud pedagógica solo es positiva si se apoya necesariamente en lo que cada adulto como aprendiz pueda 
constituir un germen de interpretante. Su libertad de iniciativa se debe canalizar hacia los objetivos deseados y excluir la pasividad, la deriva de conocimientos que no se liguen a experiencias personales, para poder apropiarse de ese nuevo objeto del conocimiento.

El discurso del profesor evidencia que es poseedor de mayor conocimiento, por lo que se entiende que posee cierto poder. De manera inconsciente, este puede transmitir al alumno su autoridad con ciertos términos o frases arrogantes que afectan sus buenas intenciones y que inciden, de manera categórica, en los procesos de cognición, socialización y aprendizaje de los alumnos (Bernstein, 1997).

El profesor, en su hacer didáctico, se adecúa a las distintas asignaturas por su singularidad y diferentes objetos del conocimiento, que lo obligan a adaptar una metodología de abordaje para su interpretación y decodificación, orientada hacia el adulto en calidad de aprendiz. No obstante, otro indicador es la comunicación interpersonal, su proxémica y kinésica en el aula.

En las universidades existe mucha deserción y repitencia del alumno en la carrera, por la falta de adaptación y transferencia de los procesos cognitivos. Una de las posibles causas es la falta de comprensión de las diferentes asignaturas por su complejidad en el propio dis- curso del objeto de estudio, es decir, los términos propios y específicos de cada objeto del conocimiento deben ser presentados por el profesor con su discurso, para la posterior decodificación por parte del alumno, el mismo que los deberá comprender para continuar con la dinámica del aprendizaje.

En las aulas universitarias se dan formas complejas de enunciación en las que el procesamiento de la información requiere de movimientos relacionales y de desplazamientos contextuales. El adulto que, como aprendiz, no comprende textos sintácticamente exigentes, se pierde al encontrar negaciones, las reversiones del lenguaje, las subordinaciones o las comparaciones. Grijelmo (2008) plantea que "sólo uno de cada cuatro universitarios reconoce las ideas secundarias y los enunciados de sintaxis compleja y muy pocos alumnos se aperciben del doble sentido de las palabras o de las expresiones figuradas" (p. 15). Al estudiante le cuesta identificar en los textos ambigüedades, contrariedades, presuposiciones o conceptos complejos. Por lo mismo, la vida intelectual del adulto como aprendiz queda reducida y él mismo se ve obligado a comprender y elaborar procesos de semiosis cognitiva que le permitan apropiarse del objeto de estudio, que puedan ser adaptados y llevados como parte importante de su proceso de aprendizaje, dependiendo de 
cómo el profesor se los haya presentado. Leer y escribir son actividades muy apetecidas en la educación universitaria, por su conexión directa con el aprendizaje. Sin embargo, son ejecutadas por todos, de manera casi analfabeta, por el poco vocabulario y el poco adiestramiento en la decodificación de distintos y asimétricos saberes acorde a las diferentes asignaturas presentadas.

Según Grijelmo (2008) las "formas elementales de escritura e intentos lectores insípidos por su literalidad y frialdad, tienden a ser la norma en las rutinas universitarias" (p. 128). La falta de comprensión y la difícil adaptación y transferencia de los nuevos conceptos adquiridos a su proceso de aprendizaje son una constante que redunda en las notas, niveles de repitencia y abandono de la carrera.

El reto del profesor es lograr, a través de un discurso pedagógico adecuado, contribuir con la construcción de ese nuevo conocimiento en el aprendiz, a través de estructuras lógicas que le permitan interactuar con su estudiante para que este, a su vez, interactúe consigo mismo, con sus pares y con la sociedad a la que pertenece y en la cual debe generar transformación y progreso.

Por el carácter singular, asimétrico e intencional en la forma de comunica- ción didáctica en los procesos de enseñanza aprendizaje, es necesario describir los diferentes códigos que actúan en los discursos y sus aportes. En tal sentido, el objetivo de este ensayo es describir los diferentes códigos que intervienen en el discurso del profesor que favorecen o no permiten el aprendizaje del adulto como aprendiz.

La construcción argumentativa del ensayo se estructura en tres momentos fundamentales que son los siguientes:
a. Discurso del profesor
b. Elementos del código
c. Tipos de códigos

La metodología que se plantea es de naturaleza documental, tipo ensayo. En este sentido, "el ensayo tiene como objetivo exponer ideas o principios relacionados con áreas de conocimiento y de la observación del autor, y el mismo puede tener intencionalidad filosófica, científica, social, cultural" (Barrera, 2000, p. 49). Como señala el Manual UPEL (2006), este tipo de investigación permite la revisión crítica del estado del conocimiento y el estudio del desarrollo teórico donde se presentan las conceptualizaciones originales y las perspectivas de los autores del ensayo. 


\section{DISCURSO DEL PROFESOR}

Dentro de los múltiples elementos que influyen en el proceso del aprendizaje universitario, uno muy importante es el discurso del profesor ante sus alumnos. Sin embargo, es un aspecto que no siempre ha sido tomado en cuenta dentro de los problemas de la didáctica de la educación superior. Debería ser así ya que de la calidad de la comunicación interpersonal y grupal que se logre en el aula dependerá de la eficiencia en la comprensión de los conocimientos y habilidades en los estudiantes. Para efectos de este estudio el constructo "discurso" se utiliza en el amplio sentido del acontecimiento comunicativo que incluye la interacción conversacional, todo el vocabulario del profesor, los textos escritos y también los gestos (proxémica y kinésica, llamados subcódigos) asociados, las imágenes utilizadas por el profesor y cualquier otra dimensión o significación semiótica o multimedia.

Es necesario incluso anotar el trabajo de Habermas (citado por Vargas, 2006) quien define el ámbito de la acción comunicativa, como "una interacción mediada por símbolos" (p. 125). Según el autor esta actividad humana tiene como núcleo las normas o reglas obligatorias de acción que definen formas recíprocas de conducta, que han de ser entendidas y reconocidas intersubjetivamente, es decir, mediante un proceso de análisis de decodificación de significados y examinar cómo se presenta este proceso en el ámbito educativo.

A mediados de los 80, Bernstein y colaboradores (1997) incorporaron en sus estudios la noción del discurso pedagógico. ¿En qué se basa esta afirmación? En que el discurso se superpone o se incluye la noción de código lingüístico, ya que no es posible elaborar discursos si no hay un código del cual se seleccionan los signos convencionales para elaborarlos. Por ello, es necesario definir qué es un código y qué tipos de códigos intervienen en los procesos de aprendizaje para lograr un consenso conceptual del objeto de estudio.

El concepto de código ha sido analizado por varios semiólogos como Pierre Guiraud (citado por Eco 1978): "... un código es un sistema de convenciones explícitas y socializadas" (p. 120). Esto quiere decir que los signos arbitrariamente seleccionados para comunicarse tienen significados convencionalmente aceptados.

Según Eco (1978), código "es un sistema de significación que reúne entidades presente y ausentes. Siempre que una cosa materialmente presente a la 
percepción del destinatario representa otra cosa a partir de reglas subyacentes, hay significación" (p. 120). El sintagma (frases u oraciones) reúne entidades presentes y el paradigma lingüístico son las entidades ausentes de las cuales se seleccionan esos signos para significar.

Chandler (citado por Eco, 1978) dice que"[e]l significado de un signo de- pende del código dentro del cual éste está situado" (p. 120). Los códigos proveen una estructura dentro de la cual los signos tienen sentido. Al crear textos o discursos, se seleccionan (nivel paradigmático) y se combinan signos (nivel sintagmático) en relación a los códigos con los que se está familiarizado.

\section{ELEMENTOS DEL CÓDIGO}

El código es un sistema de relaciones y existen dos fundamentales: las sintagmáticas y paradigmáticas, según Saussure (citado por Arellano, 1977). Esta distinción de la organización de los signos depende de los postulados teóricos de los semióticos. Los estudiosos del lenguaje definen a las frases y oraciones como sintagmas lingüísticos, en donde la combinación de los elementos es hipotáctica, es decir, de distintas categorías enlazadas en una frase, u oración.

Según la Real Academia de la Lengua Española (2006), la palabra sintagma es una palabra compuesta del prefijo griego sýn- (con, junto con, juntos) y el sustantivo griego tágma (orden, disposición, colocación, agrupación, ordenamiento de elementos).

Una relación sintagmática implica una combinación ordenada de significantes interactuantes que forman un todo con significado. Tienen como fundamento el carácter lineal de la lengua, por lo cual no se puede pronunciar dos palabras a la vez sino una detrás de otra. Entonces, el sintagma se compone de dos o más términos consecutivos que adquieren su valor porque se oponen al que le precede o antecede.

En definitiva, la relación sintagmática entre los diferentes elementos es una cadena de signos. El sintagma en el discurso, no solo es de los signos lingüísticos, sino de aquellos que no lo son, tales como la manera de vestirse del profesor, (sintagma visual que también forma relaciones hipotácticas), la manera en cómo son dichos los discursos, todo el vocabulario del profesor, los textos escritos y los gestos (proxémica y kinésica, llamados subcódigos) y toda la dimensión de significación o multimedia, para lo que las matrices de semiótica 
permitirán su apreciación más adecuada.

El profesor es el hacedor del discurso, combina los signos acorde a una coherencia sintáctica y semántica para poder expresar las ideas y objetos de estudio a tratar a través de sintagmas. Por ejemplo:
teléfono
el teléfono
el teléfono de la oficina
el teléfono de la oficina está sonando
el teléfono de la oficina está sonando continuamente

Sin embargo, esta es la parte visual o sensorial del discurso, mientras que la relación paradigmática de los signos lingüísticos es totalmente abstracta.

Con el significado etimológico el término paradigma se origina en la palabra griega paradeigma, que significa modelo o ejemplo. A su vez, tiene las mismas raíces de la palabra demostrar. De hecho, la definición de paradigma, según la Real Academia de la Lengua Española (2006), es cada uno de los esquemas formales en que se organizan las palabras nominales y verbales para sus respectivas flexiones.

En el presente ensayo las definiciones lingüísticas no incluyen la mayoría de los conceptos desarrollados por Kuhn (1975). No obstante, dado que este término se utiliza en enseñanzas técni- cas en castellano de forma generalizada con la definición aquí expresada, no se puede considerar que esta interpretación del vocablo paradigma no sea acertada, al menos, a efectos prácticos.

Un paradigma lingüístico es un conjunto de unidades que pueden conmutarse entre sí, es decir, que pueden manifestarse en el mismo contexto $y$, por tanto, las unidades de un paradigma están en oposición entre sí y rivalizan por manifestarse en el sintagma (Martínez, 1997). Es por tanto un conjunto de unidades del mismo nivel lingüístico en relación de contraste.

Los paradigmas y los sintagmas están sometidos a dos operaciones: la elección y la combinación, en el habla o actuación comunicativa, todo hablante elige una unidad de entre las que constituyen el conjunto del paradigma y la combina en el sintagma con la unidad siguiente de otro paradigma, es un modelo y, aplicado en este sentido a la lingüística, en especial a la gramática tradicional, se llama paradigma a cada una de las categorías lingüísticas en las que se divide la lengua (nombres, adjetivos, verbos, etc.).

\section{Así, la relación paradigmática} entre un elemento y los que lo podrían sustituir en otro contexto en la misma cadena y que se excluyen mutuamente es consideración vertical de la cadena lingüística u oración (Martínez, 1997). Por ejemplo: 
El -- salta de alegría.

se puede formar frases como

El padre salta de alegría.

El niño salta de alegría.

El hombre salta de alegría.

El perro salta de alegría.

El amigo salta de alegría

El paradigma lingüístico es el conjunto de signos miembros de una categoría definitoria, cada uno con su significado. Esta relación se produce ya que las palabras que tienen algo en común se asocian en la memoria formando grupos donde existen diversas relaciones, "estas relaciones llamadas asociativas ya no se basan en la extensión su sede está en el cerebro y forman parte de ese tesoro interior que constituye la lengua de cada individuo" (de Saussure, citado por Arellano, 1977, p. 136). De la misma forma, en esta investigación los paradigmas que conforman el código del discurso no sólo serán de tipo lingüístico, sino los paradigmas del profesor de los cuales selecciona no sólo su manera de hablar sino sus gestos y modo de decir las cosas, incluso la selección de los colores para sus presentaciones y manera de vestir, que inciden en cómo el alumno decodifica el todo del discurso pedagógico del profesor. Por ejemplo:
En el lenguaje natural: los verbos, los sustantivos.

En el lenguaje audiovisual: disolvencias, cortes.

En el lenguaje de las artes gráficas: color, tono.

La codificación es un acuerdo entre los usuarios del signo que reconocen la relación entre el significante y el significado, y la representan en el empleo del signo (Guiraud, citado por Eco, 1978). Esta convención puede ser más o menos amplia, y más o menos precisa. Un signo monosémico (de un solo significado) es más preciso que un signo polisémico (varios significados). Para Eco (1978), "cuanto más vaga se torna la convención, el valor del signo varía en mayor medida con los diferentes usuarios" (p. 129). Esta convención está asociada a un grupo de individuos que maneja el código.

Tanto los profesores como los adultos aprendices establecen un proceso cultural mediante el cual se codifican convenciones en la interpretación de ciertos signos, a través de relaciones sintagmáticas y paradigmáticas. Por ejemplo, graficando la relación sintagmática y paradigmática, según Martínez (1997).

En el siguiente gráfico de la relación sintagmática el profesor y el alumno seleccionan sustantivos, verbos, adjetivos, adverbios, del conjunto para- 
digmático. Las categorías gramaticales que se utilizan para construir frases y oraciones, siempre deben estar en sentido horizontal, en el lenguaje oral y escrito, aunque el concepto de sintagma no solo se utilice en frases y oraciones, sino que también puedan ser combinaciones de colores en un afiche, en una fotografía. Varían los códigos de donde toman las categorías correspondientes. En cuanto a la lingüística, se ilustra de la siguiente manera:

Grafico 1

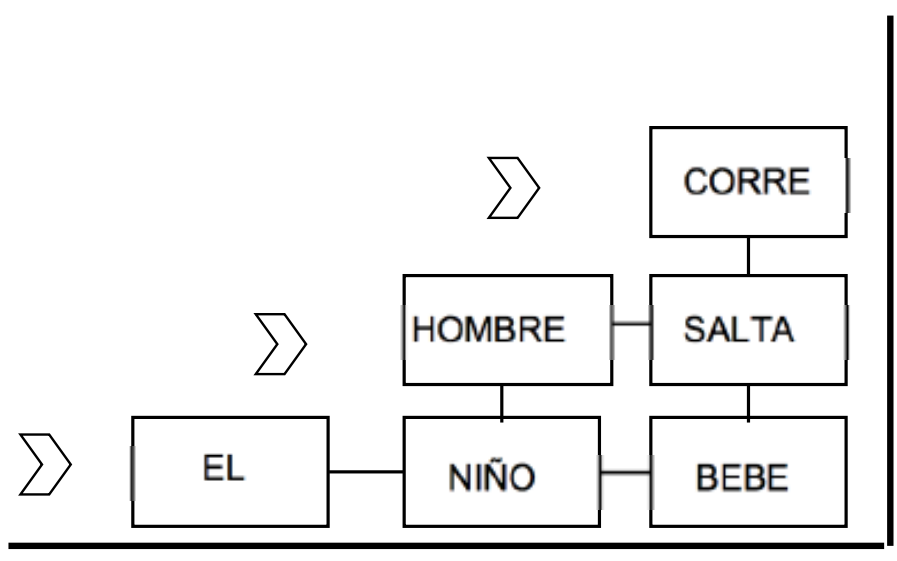

Relación sintagmática

Fuente: Römer y Valdivieso, 2005

El eje sintagmático es el eje de la combinación.

La relación sintagmática puede ser espacial o temporal.

El eje del paradigma lingüístico es lo que está en la mente de cada ser humano, independientemente del idioma que hable. Ahí se ubican todos los signos lingüísticos debidamente categorizados y clasificados para ser seleccionados para formar oraciones y frases, ya sea a nivel oral o escrito.

No solo se limita al paradigma lingüístico, este puede ser en cuanto al código de bienes de donde se selecciona la manera de vestirse, las categorías paradigmáticas que permiten combinar elementos para tomar fotografías, la combinación de colores en las presentaciones, en afiches, en fin. 
Se ilustra de la siguiente manera:

Grafico 2

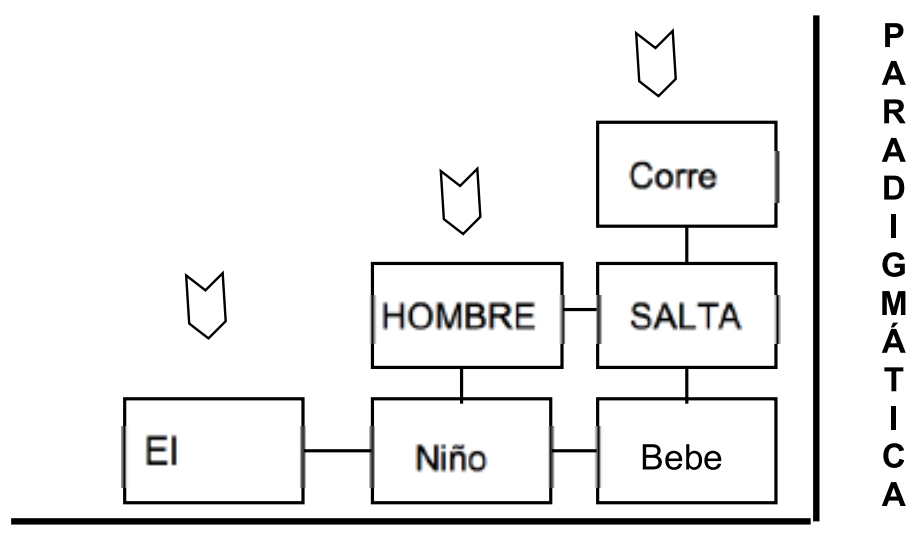

Relación paradigmática

Fuente: Römer y Valdivieso, 2005

El eje paradigmático es el eje de la selección.

El análisis discursivo a nivel sintagmático y paradigmático se explica a la luz de la semiótica que ofrece una ma- triz de comprensión de cómo funciona y se integran para la elaboración de discursos, basado en autores como Hjemslev, que basa su planteamiento a su vez en el de Saussure, (citados por Cobley 2000).

\section{TIPOS DE CÓDIGOS}

El código lingüístico es un código social que incluye los subcódigos fonológicos (asociados a producción y uso de los fonemas o sonidos), sintácticos (referentes a las normas de combinación de signos), lexicales (referentes al vocabulario), paralingúísticos (grado de intensidad, altura tonal, tempo del habla, la respiración y las pausas del habla entre otros, incluye las señas extralingüísticas como la mímica y los gestos), y prosódicos (todos los fenómenos que afectan la 
duración, la altura tonal, la energía dinámica, las relaciones de duración y las diferencias tonales), los también llamados subcódigos proxémicos y kinésicos.

El código proxémico es el que utiliza el espacio entre el emisor y el receptor, la distancia que se mantiene con respecto al interlocutor tiene una significación específica. Este código varía según cada cultura. Por ejemplo, para culturas como la japonesa es importante guardar determinada distancia entre las personas, muy diferente a Latinoamérica donde la cercanía y el contacto físico son parte importante de la comunicación.

El código kinésico utiliza los gestos y la mímica para comunicarse. Este código está muy relacionado con el habla y el código prosódico. Cuando se aprecia que existen diferencias marcadas entre los códigos textuales y gestuales, se comprende que en la comunicación existe convivencia entre diferentes códigos. Todos estos códigos forman parte del discurso del profesor y también del adulto como aprendiz.

Si en un salón de clases están reunidas 30 personas, estas tendrán varios códigos comunes convencionales. Sin embargo, la interpretación de cada uno determinará los procesos comunicativos. Bernstein (1997) los define como códigos sociolingüísticos.

Ahora, cómo funcionan todos estos códigos en la conformación del dis- curso del profesor, a saber, el concepto de código sociolingüístico se refiere a la estructuración social de los significados y a sus manifestaciones lingüísticas en contextos diferentes pero relacionados. Vygotsky (1979) señala que entre más estrecha sea la identificación entre los hablantes mayor será el conjunto de intereses compartidos y será más probable que el discurso tome una forma particular.

Es importante definir la palabra sociedad que debe incluir las interacciones locales cara a cara detectadas como las estructuras más globales, en las que está inmerso tanto el alumno como el profesor; que se definen de forma diversa en términos de grupos, de relaciones de grupo (como las de dominación y desigualdad), de movimientos, de instituciones, de organizaciones, de procesos sociales o de sistemas políticos, junto con otras propiedades más abstractas de las sociedades y de las culturas.

En estas relaciones, la intención de la persona participante puede darse por supuesta, pues el discurso se despliega sobre un fondo de presuposiciones comunes, de una historia común, y de intereses comunes o de un objeto de estudio que está siendo discutido.

Como resultado, surge la necesidad de explicitar o de elaborar los significados a través de selecciones sintácticas, la estructura lógica del discurso. Además, si el profesor desea individualizar su co- 
municación, recurrirá sin duda a diversos procedimientos expresivos como gestos y signos multimedia, que acompañen su proceso comunicativo.

En estas condiciones, es probable que el discurso tenga un carácter fuertemente metafórico. El profesor prestará más atención a la manera en cómo una cosa se dice o al momento en que se dice. Además, el silencio tiene un gran rol expresivo. A menudo, el discurso no puede ser comprendido si se hace abstracción del contexto y este no puede ser descifrado por aquellos que no comparten la historia de las relaciones entre los sujetos (en este caso de los alumnos o los aprendices). Por ejemplo, si los alumnos desconocen algún significado de palabras que sean seleccionadas del paradigma lingüístico para elaborar el sintagma por parte del profesor, el alumno se quedará solo con un significante sin un contexto y significado, donde surge la falta de comprensión.

Los códigos sociolingüísticos de los dos actantes en el proceso aprendizaje actúan selectivamente sobre los significados que son enunciados los cuales a su vez afectan las escogencias, la combinación y selección en la elaboración del discurso.

Los códigos sociolingüísticos, como sistemas de categorías convencionales, determinan la comunicación, siempre y cuando haya un contexto común que genere la permanencia de un nuevo conocimiento adquirido por parte del alumno. Además, hay que tomar en cuenta lo que es el referente, los campos de experiencia, los marcos de conocimiento y la memoria a corto y a largo plazo como elementos dentro del discurso del profesor.

No hay que dejar de lado al referente-que es la realidad-sobre la cual se produce la comunicación y, por lo tanto, es la generadora del conocimiento. La generadora del significado es parte del mundo real, aplicado a este ámbito de estudio, es el objeto del conocimiento sobre el que se diserta en el aula y que también lo que otros autores definen como el Marco de Conocimiento. Para Cuenca (1999) es el saber de sí mismo y del mundo que rodea a los sujetos en interacción, como también es la cosmovisión de los participantes e interlocutores. Al ubicarse los marcos de referencia, es decir, cuánto saben los interlocutores del referente que está en discusión o en proceso de discernir, los procesamientos de la información y su respectiva selección de lo más relevante que permite la derivación y, por último, la construcción: la transformación del nuevo contenido (Niño, 2004).

No se puede desligar de este campo a la memoria a corto y largo plazo. Este elemento es fundamental en el procesamiento de la información por- 
que permite almacenarla y tenerla a la disponibilidad en los futuros actos de habla.

También están presentes los Campos de Experiencia, que son el conjunto de ideas, creencias, valoraciones intereses, opiniones, deseos, cultura y condiciones naturales que fungen como fuentes de comunicación o inciden en ella. Un discurso está inmerso en los campos de experiencia de los interlocutores de un modo de comunicación. En el caso que ocupa esta investigación, las experiencias provienen tanto de los profesores como de los alumnos que rodean al objeto de estudio: estas experiencias actúan como filtros de la información

Los códigos sociolingüísticos implican una organización y una significación de la sociedad porque son rasgos distintivos de una cultura y tienen como vehículo fundamental al hombre y sus acciones. Según Giraud (1977) "la vida social es un juego en el cual el individuo representa su propio papel: el patriarca, el tío tutelar, el hijo pródigo o el amigo fiel. Por otra parte, el signo social es un signo de participación" (p. 45).

La clasificación más usada de los códigos sociales es la brindada por Barthes (1971), la cual divide a los códigos en:

1. Códigos Lingüísticos: Lenguaje verbal (sub-códigos fonológico, sintácti- co, prosódico y paralingüístico)

2. Códigos Corporales (contacto, proximidad, apariencia expresión facial)

3. Códigos de Bienes (la moda, la ropa, automóviles)

4. Códigos de Comportamiento (protocolos, rituales, juegos)

5. Códigos Textuales (representacionales)

Textuales:

6. Códigos científicos (matemáticas, física, química)

7. Códigos estéticos (poesía, artes dramáticas, pintura e incluye realismo, romanticismo)

8. Códigos de género, retórica y estilístico narrativo (tema, personaje, acción, diálogo, espacio), argumento, nudo.

9. Códigos de Medios de Masas fotográficos, audiovisuales, fílmico, radio, prensa; tanto técnicos como convencionales.

10. Códigos Interpretativos aunque hay controversia con respecto a esta tipificación se le llama interpretativos a:

a. Códigos Perceptuales se refieren a la percepción visual en un primer nivel están asociados a la visión, es decir, a cómo se perciben los elementos primarios de lo visible: el color, la luz, los bordes visuales y la variación en el tiempo de los fenómenos luminosos. En un segundo nivel se inscriben en lo visual propiamente dicho: 
la percepción visual del espacio y el tiempo.

b. Códigos Ideológicos estos incluyen la libertad, el patriarcado, la raza, la clase, la religión, el materialismo, el capitalismo, el comunismo, el cientificismo y el feminismo.

\section{CONCLUSIONES}

El profesor, a través de su discurso, manifiesta muchos más códigos y discursos, y deberá ser capaz de crear en el alumno la formación de nuevos patrones de pensamiento que constituyan una fuente de referencia para definir lo aceptable o no en las áreas de investigación y conocimiento de la realidad. He ahí la importancia de la utilización adecuada del discurso pedagógico empleado por los docentes.

Por lo expuesto, el discurso pedagógico es un discurso de poder que ejerce el profesor. Tanto él como sus alumnos se convierten en emisores y receptores a la vez y, acorde a su actuación y cognición, provocan una mediación en la comunicación de los mensajes. A medida que dicho mensaje circula, cada uno de ellos lo va resignificando a partir de las construcciones personales que realiza.

Por otro lado, el adulto aprendiz participa de una actividad didáctica específica, transitando por diferentes niveles de comunicación. El primero es el intraindividual e intrapsicológico (Pérez,
1985) que permite revisar sus conocimientos y referentes. Posteriormente, por intercambio con los otros, se pasa a un nivel interindividual, que provoca la circulación del mensaje que se explicita y comparte en el aula. Se produce el fenómeno de semiosis cognitiva (Gardner, 1987), entendiéndose la cognición como un fenómeno que implica tanto la cognición personal como la cognición social, las creencias y los objetivos, así como las valoraciones y las emociones, junto con cualquier otra estructura, representación o proceso mental o memorístico que haya intervenido en el discurso y en la interacción en el aula

El profesor trae al aula y recontextualiza, creando situaciones para su desarrollo. Dependerá de la ocurrencia de dichas situaciones de clase que el aprendiz logre re-des-contextualizarlos, (Bernstein, 1997), es decir, construir significados y procesos personales.

En esto radica precisamente el efecto de poder de un discurso: la capacidad de poner en marcha un mecanismo de creencias, la adhesión de un 
nuevo patrón o paradigma para ver las cosas. En las creencias que generan las distintas cátedras o disciplinas y, que a su vez, cada una genera dentro de cada espacio curricular, se opera un discurso que actúa como un crisol a través del cual pasa el conocimiento con conceptos, contenidos y relaciones específicas y definidas, que derivan de un pensamiento y conocimiento del profesor, ya que por el tipo de discurso el docente, puede o no abrirse a lo posible. De ese modo se presenta la posibilidad que tiene el profesor de articular conocimiento y futuro (Bernstein, 1997). El análisis del discurso pedagógico, en resumen, se basará en el estudio y utilización del lenguaje y la comunicación humana en el ámbito educativo. 


\section{REFERENCIAS BIBLIOGRÁFICAS}

Arellano, F. (1977). Historia de la Lingüística, Bajo el signo del estructuralismo. Caracas: UCAB.

Arellano, F. (1977. Historia de la Lingüística (tomo I y tomo II). Caracas: UCAB.

Barthes, R. (1971). Elementos de Semiología. Madrid: Corazón.

Barrera, F. (2000). Sugerencias para redactores, comunicadores e investigadores. Caracas: SYPAL

Bernstein, B. (1983). La educación no puede suplir las fallas de la sociedad. Cali: Centro de Traducciones UNIVALLE.

Bernstein, B. (1997). La estructura del discurso pedagógico. Madrid: Morata. 1997.

Cobley, P., Jansz L., (2004). Semiótica para principiantes, Buenos Aires: Longseller.

Cuenca, M. y Hilferty, J. (1999). Introducción a la lingüística cognitiva. Barcelona: Ariel Lingüística.

Diccionario de la Real academia de la Lengua 2006

Eco, U. (1978), La estructura ausente. Introducción a la semiótica. BarceIona: Lumen.

Eco, U. (1978). Tratado de semiótica general. México: Nueva Imagen y Lumen.
Gardner Howard (1987), François Rastier (1991) y Georges Vignaux (1992) entre otros y a la publicación, desde 1987, de Cognitive Science, journal of the Cognitive Science Society, así como las publicaciones de la Association des Recherches Cognitives.

Greimas; Courtes y otros (1990). Semiótica, Biblioteca románica hispánica. Madrid: Gredos.

Grijelmo, A. (2008). Defensa apasionada del idioma español. Madrid: Taurus Santillana.

Guiraud, P. (1972). La Semiótica. Madrid: Gredos.

Habermas, J. (1990). Teoría de la Acción Comunicativa: Complementos y Estudios Previos. Madrid: Cátedra.

Hjelmslev, L. (1971). Prolegómenos a una teoría del lenguaje. Madrid: Gredos.

Kuhn, T. (1975). La estructura de las revoluciones científicas. México: Fondo de Cultura Económica.

Martínez, L. (1997). Diccionario de lingüística moderna. Barcelona: Editorial Ariel.

Niño, V. (2002). Semiótica y Lingüística. Colombia: ECOE Ediciones.

Pérez, A. (1985). La comunicación Didác- 
tica. Málaga: Universidad de Málaga.

Ribeiro, L. (2002), La comunicación Eficaz, Barcelona, España, 2000

Römer y Valdivieso H. (2007). Material digital de la asignatura de Semiótica. Caracas: UCAB.

Saussure, F. (1986). Curso de Lingüística general. Madrid: Alianza Editorial. Universidad Pedagógica Experimental Libertador (2006). Manual de Tra- bajos de Grado de Especialización y Maestrías y Tesis Doctorales. Vicerrectorado de Investigación y Postgrado. Caracas-Venezuela.

Vargas-Mendoza, J. (2006). Teoría de la Acción Comunicativa: Jurgen Habermas. México: Asociación Oaxaqueña de Psicología A.C.

Vigotsky L. (1979). El Desarrollo de los procesos psicológicos superiores. Barcelona: Crítica. 